\title{
An analysis on choices of contraception
}

\author{
Manidip Pal ${ }^{1 *}$, Suman K. Roy ${ }^{2}$ \\ ${ }^{1}$ Department of Obstetrics and Gynecology, ${ }^{2}$ Department of Community Medicine, College of Medicine and JNM \\ Hospital, WBUHS, Kalyani, Nadia, West Bengal, India
}

Received: 06 May 2018

Accepted: 30 May 2018

\section{*Correspondence:}

Dr. Manidip Pal,

E-mail: manideep2b@yahoo.com

Copyright: () the author(s), publisher and licensee Medip Academy. This is an open-access article distributed under the terms of the Creative Commons Attribution Non-Commercial License, which permits unrestricted non-commercial use, distribution, and reproduction in any medium, provided the original work is properly cited.

\section{ABSTRACT}

Background: Contraception is a matter of choice by the end users. The choice varies time to time. Present study tries to find out which type of contraceptive measure people prefer nowadays.

Methods: This is a retrospective observational study conducted at College of Medicine \& JNM Hospital, WBUHS, Kalyani, India. The contraceptive performance data of the hospital are collected from the computerised data entry register. The study period was from January 2015 to December 2017. Total number of different contraceptive methods (OCP, condom, IUCD, MTP, tubal ligation etc.) accepted by the people were found out. Data was then analysed in comparison to total number of contraception with each other by student ' $t$ ' test and chi square test.

Results: It is found that condom use is significantly increased from 2015 to 2017 ( $\mathrm{p}<0.00001$ ). OCP use is significantly decreased from 2015 to 2017 ( $\mathrm{p}<0.00001$ ). IUCD insertion significantly increased from 2015 to 2017 $(\mathrm{P}<0.00001)$ and tubal ligation significantly decreased from 2015 to 2017 ( $\mathrm{p}<0.00001)$.

Conclusions: Contraception choice preference is shifting towards LARCs (long acting reversible contraceptives).

Keywords: Condom, IUCD, LARCs, OCP

\section{INTRODUCTION}

Contraception is a matter of choice by the end user. Different methods are available with their respective benefit. Cafeteria approach helps the eligible couple to decide about their contraceptive method after knowing the pros and cons of different methods.

Contraceptives $>99 \%$ effective if used correctly: contraceptive implant, intrauterine system (IUS), intrauterine device (IUD), female \& male sterilisation; Contraceptives $>99 \%$ effective if always used correctly, but $<95 \%$ effective with typical use: contraceptive injection, combined oral pill (OCP), progestogen-only pill, contraceptive patch, vaginal ring; contraceptives 99\% effective if used according to instructions: symptothermal method of natural family planning; Contraceptives $98 \%$ effective if used correctly: male condom; contraceptives $95 \%$ effective if used correctly: female condom; contraceptives $92-96 \%$ effective if used correctly: diaphragm or cap with spermicide. ${ }^{1}$

Apart from these knowledge other factors also influence the choices of contraception e.g. influences from social media and friends, their partners and religious belief, educational status etc. ${ }^{2,3}$ In the TRIO study at Kenya and South Africa uses of daily OCP, monthly injections and monthly vaginal ring were compared and it was found that mean choices for monthly injections were significantly higher $[4.3(\mathrm{SD}=1.0)]$ in compare to the OCP [3.0 $(\mathrm{SD}=1.3)]$ and vaginal rings [3.3 $(\mathrm{SD}=1.4)]$ $(\mathrm{p}<0.001)$; mean choices for vaginal rings were significantly higher than for OCP $(\mathrm{p}=0.013){ }^{4}$ Present study is conducted to know what the couples attending our hospital prefer these days. 


\section{METHODS}

This is a retrospective observational study conducted at the College of Medicine and JNM Hospital, WBUHS, Kalyani, Nadia, West Bengal, India. The study period was from January 2015 to December 2017. The data was obtained from the computerized data entry register of the hospital. Yearly data (January-December) of 2015 and 2017 were collected from the HMIS (Health Management Information System) sheet for annual performance comparison. Inclusion criteria were data entered under the "Family planning" heading of the HMIS sheet. Rest of the data were not relevant to the contraception, hence excluded. They were distributed under different types of contraception in ' $x$ ' axis and years and months in ' $y$ ' axis. Data was then evaluated by the student ' $t$ ' test and Chi-square test and ' $p$ ' values obtained. Student ' $t$ ' test was applied while respective contraceptive methods were compared with the total contraceptive uses e.g. IUCD with total contraceptive uses, OCP with total contraceptive uses etc. and Chi-square test was applied while comparing the IUCD with OCP. The study is in accordance with the Institutional Ethics Committee.

\section{RESULTS}

In 2015 barrier contraceptives distributed was 22617, OCP cycle $(1$ strip $=1$ cycle) distributed was 14360 , IUCD inserted 230, MTP done 55 and tubal ligation performed in 653 women. At a glance it appeared that couples preferred combined oral contraceptive pills, condoms at that time and good numbers of women were undergoing tubal ligation. Month wise performance is showed in the Table 1 .

Table 1: Contraception 2015.

\begin{tabular}{|c|c|c|c|c|c|c|c|c|c|c|c|c|}
\hline \multirow{2}{*}{$\begin{array}{l}\text { Year } \\
\text { and } \\
\text { Month }\end{array}$} & \multirow{2}{*}{$\begin{array}{l}\text { Condom } \\
\text { (pieces } \\
\text { dis- } \\
\text { tributed) }\end{array}$} & \multirow{2}{*}{$\begin{array}{l}\text { OCP } \\
\text { (cycle } \\
\text { dis- } \\
\text { tributed) }\end{array}$} & \multicolumn{5}{|l|}{ IUCD } & \multirow[b]{2}{*}{ MTP } & \multicolumn{4}{|c|}{ Tubal ligation } \\
\hline & & & Interval & PPIUCD & PAIUCD & Total & $\begin{array}{l}\text { IUCD } \\
\text { removal }\end{array}$ & & $\begin{array}{l}\text { Inter } \\
\text { val }\end{array}$ & $\begin{array}{l}\text { Post } \\
\text { abortion }\end{array}$ & Cesarean & Total \\
\hline \multicolumn{13}{|l|}{2015} \\
\hline Jan & 2500 & 520 & 13 & 0 & 0 & 13 & 0 & 5 & 32 & 0 & 21 & 53 \\
\hline Feb & 2010 & 1700 & 9 & 0 & 0 & 9 & 2 & 8 & 21 & 0 & 41 & 62 \\
\hline Mar & 2260 & 1650 & 16 & 0 & 0 & 16 & 0 & 6 & 26 & 0 & 43 & 69 \\
\hline Apr & 2560 & 1510 & 9 & 0 & 0 & 9 & 0 & 4 & 31 & 0 & 21 & 52 \\
\hline May & 2340 & 1480 & 4 & 16 & 0 & 20 & 0 & 4 & 33 & 0 & 23 & 56 \\
\hline Jun & 1275 & 960 & 5 & 15 & 0 & 20 & 0 & 4 & 27 & 0 & 25 & 52 \\
\hline Jul & 2130 & 1420 & 6 & 0 & 0 & 6 & 0 & 4 & 20 & 0 & 31 & 51 \\
\hline Aug & 2010 & 1040 & 4 & 32 & 0 & 36 & 0 & 5 & 34 & 0 & 23 & 57 \\
\hline Sep & 2010 & 1020 & 5 & 25 & 0 & 30 & 0 & 4 & 25 & 0 & 31 & 56 \\
\hline Oct & 2012 & 1024 & 7 & 25 & 0 & 32 & 3 & 5 & 21 & 0 & 36 & 57 \\
\hline Nov & $\begin{array}{l}0 \text { (short } \\
\text { supply) }\end{array}$ & 996 & 8 & 13 & 0 & 21 & 0 & 3 & 17 & 0 & 26 & 43 \\
\hline Dec & 1510 & 1040 & 7 & 11 & 0 & 18 & 1 & 3 & 20 & 0 & 25 & 45 \\
\hline Total & 22617 & 14360 & 93 & 137 & & 230 & 6 & 55 & 307 & & 346 & 653 \\
\hline
\end{tabular}

The total number contraception had been increased from 37915 (2015) to 52892 (2017). In 2017 the total condom pieces distributed was 42297, OCP cycle distributed 6077 , number of women received IUCD was 4015, MTP was done in 110 cases and tubal ligation was performed in 393 women. At a glance, in 2017, couples preferred condom and IUCD than OCP and tubal ligation. Month wise performance is showed in Table 2.

While comparing the total contraception with the individual type of contraception it was found that 1) use of condom is significantly increased from 2015 to 2017 $(\mathrm{p}<0.00001)$; 2) OCP use is significantly decreased from 2015 to $2017 \quad(\mathrm{p}<0.00001)$; 3) IUCD insertion is significantly increased from 2015 to 2017 ( $\mathrm{P}<0.00001)$; 4) Tubal ligation is significantly decreased from 2015 to 2017 ( $p<0.00001$ ). As such MTP numbers are less in our institution, still there is mild increase in number from
2015 to 2017 ( $\mathrm{p}<0.05$ ). While comparing data of IUCD and OCP among themselves, being more commonly used temporary method with less failure rate, it was found that IUCD insertion was significantly increased from 2015 to $2017(\mathrm{p}<0.00001)$.

\section{DISCUSSION}

India, the second most populous country of the world, harbours $17.5 \%$ of the world's population. Coincidentally it also houses almost $17.3 \%$ of the world's protected couples and $20 \%$ of world's eligible couples with unmet need. ${ }^{5}$ So propagating correct information about different types of contraceptive methods is very essential and which has been done effectively throughout the year. As a result people are gaining more and more information about different types of contraception - their indications, contraindications, long term benefits, complications etc. 
This knowledge is helping them to take justified decision about the type of contraception they want. It has been observed that there is a shift of choices of the couples regarding the type of contraception-more in favour of long acting reversible contraception.

Long-acting reversible contraceptives (LARCs) are very effective methods of contraception. LARCs include the copper $\mathrm{T}(\mathrm{Cu} \mathrm{T}$ 380A), LNG IUS (Levonorgestrel intrauterine system) and hormonal implant which are effective for 10, 4 and 3 years respectively. They can prevent unwanted pregnancy up to 20 times better than oral combined contraceptive pills, patches and vaginal rings. ${ }^{6}$ In the US increases in the prevalence of LARC uses was observed even among sexually experienced nulliparous women [2008 to 2012 (0.8\% vs. $3.8 \%)$ $\mathrm{p}<0.0001$ and 2012 to 2014 (3.8\% vs. $5.7 \%) \mathrm{p}=0.09]{ }^{7}$ LARCs methods can bring 'typical use' failure rates more in line with 'perfect use' failure rates. ${ }^{8}$

Table 2: Contraception 2017.

\begin{tabular}{|c|c|c|c|c|c|c|c|c|c|c|c|c|}
\hline \multirow[b]{2}{*}{$\begin{array}{l}\text { Year \& } \\
\text { Month }\end{array}$} & \multirow{2}{*}{$\begin{array}{l}\text { Condom } \\
\text { (pieces } \\
\text { dis- } \\
\text { tributed) }\end{array}$} & \multirow{2}{*}{$\begin{array}{l}\text { OCP } \\
\text { (cycle dis- } \\
\text { tributed) }\end{array}$} & \multicolumn{5}{|l|}{ IUCD } & \multirow[b]{2}{*}{ MTP } & \multicolumn{4}{|c|}{ Tubal ligation } \\
\hline & & & Interval & PPIUCD & PAIUCD & Total & $\begin{array}{l}\text { IUCD } \\
\text { removal }\end{array}$ & & Interval & $\begin{array}{l}\text { Post } \\
\text { abortion }\end{array}$ & Cesarean & Total \\
\hline \multicolumn{13}{|l|}{2017} \\
\hline Jan & 4800 & 380 & 4 & 274 & 0 & 278 & 0 & 3 & 0 & 0 & 13 & 13 \\
\hline Feb & 4200 & 330 & 18 & 349 & 0 & 367 & 2 & 3 & 0 & 0 & 20 & 20 \\
\hline Mar & 4500 & 360 & 2 & 348 & 0 & 350 & 0 & 11 & 0 & 0 & 22 & 22 \\
\hline Apr & 3200 & 320 & 4 & 225 & 0 & 229 & 2 & 6 & 8 & 0 & 31 & 39 \\
\hline May & 3400 & 740 & 5 & 122 & 6 & 133 & 1 & 8 & 11 & 0 & 40 & 51 \\
\hline Jun & 4050 & 610 & 4 & 226 & 8 & 238 & 2 & 16 & 5 & 1 & 23 & 29 \\
\hline Jul & 1485 & 598 & 19 & 319 & 0 & 338 & 7 & 6 & 13 & 1 & 34 & 48 \\
\hline Aug & 2160 & 565 & 3 & 435 & 5 & 443 & 5 & 12 & 4 & 4 & 35 & 43 \\
\hline Sep & 2172 & 544 & 4 & 464 & 0 & 468 & 6 & 16 & 5 & 2 & 35 & 42 \\
\hline Oct & 4000 & 550 & 8 & 408 & 0 & 416 & 7 & 12 & 0 & 0 & 29 & 29 \\
\hline Nov & 4050 & 560 & 7 & 415 & 0 & 422 & 8 & 9 & 0 & 0 & 31 & 31 \\
\hline Dec & 4280 & 520 & 7 & 326 & 0 & 333 & 10 & 8 & 3 & 0 & 23 & 26 \\
\hline Total & 42297 & 6077 & 85 & 3911 & 19 & 4015 & 50 & 110 & 49 & 8 & 336 & 393 \\
\hline
\end{tabular}

In 2008, the Government of India took step to revitalize the postpartum intrauterine contraceptive device (PPIUCD) services. This step was needed to address the high unmet need for postpartum family planning services beyond sterilization, and help improve spacing between pregnancy, which would contribute in improving maternal and child morbidity and mortality status throughout the country. ${ }^{9}$ Government is supplying $\mathrm{Cu}$ T 380A for PPIUCD. The overall acceptance rate among those eligible for PPIUCD was $39 \%$ (95\% confidence interval $[\mathrm{CI}]$ : $35.1-42.9) .{ }^{10}$ Women undergoing cesarean section were more frequently accepting PPIUCD than the women who had normal vaginal delivery. Majority $(67.12 \%)$ accepters told that they accepted IUCD as it is a reversible method. ${ }^{11}$ Women's satisfaction after wearing PPIUCD was $91.7 \%$ after 6 weeks, $92.9 \%$ after 3 months, and $95.6 \%$ after 6 months. ${ }^{12}$ Nearly all women $(99.6 \%)$ were satisfied with IUCD at the time of insertion and $92 \%$ were satisfied at 6 week follow-up visit. ${ }^{13}$ Continuation rate after 1 year was $91 \% .{ }^{14}$ PPIUCD is an appealing approach and may become the best choice as post-partum contraception after vaginal as well as cesarean delivery. ${ }^{15}$

In present study also IUCD insertion is significantly increased from 2015 (230) to 2017 (4015) $(\mathrm{P}<0.00001)$.
Thanks to our govt. Family planning counsellor and counsellor of FIGO-FGOGSI PPIUCD project for sharing more and more knowledge about different types of contraception among the people via counselling every day. Both the team are doing excellent work.

Contraceptive choice project in St. Louis revealed that when provided with proper counselling and their choice of contraceptive method at no cost, $67 \%$ of eligible women chose an IUCD or implant, as compared with less than $6 \%$ choosing these methods in the general population. ${ }^{16}$ The goals of the Healthy People 2020 initiative include a $10 \%$ increase in the proportion of pregnancies that are intended and a $10 \%$ decrease in the number of conceptions that occur within 18 months after a woman's previous delivery. Provision of contraception as a preventive care service and eliminating its cost sharing will be an instrumental step toward achieving this goals. ${ }^{17}$

Department of Health \& Family Welfare, Govt. of India, has already started the free supply of $\mathrm{Cu} \mathrm{T} 380 \mathrm{~A}, \mathrm{Cu} \mathrm{T}$ 375 along with existing free supply of condom, OCP etc. So knowing the contraception choices of the people is going to help the local administrator to get requisite supply of the respective types of contraception in advance 
so that adequate family planning care can be continued smoothly.

The methods which offer long-term protection and need not to be remembered by the couple everyday/time are gaining popularity nowadays. But it should be kept in mind that condom protect against STIs (sexually transmitted diseases) also, whereas other methods does not have this property. So ideal situation would be use LARCs and simultaneously use condom during the time of partner's STI.

\section{ACKNOWLEDGMENTS}

Our sincere thanks go to Mrs. Debjani Dutta, Data entry operator, College of Medicine \& JNM Hospital, WBUHS, Kalyani, Nadia, West Bengal.

Funding: No funding sources Conflict of interest: None declared

Ethical approval: The study was approved by the Institutional Ethics Committee

\section{REFERENCES}

1. Available at: https://www.nhs.uk/conditions/contraception/whichmethod-suits-me/. Accessed on 1 April 2018

2. Kahramanoglu I, Baktiroglu M, Turan $\mathrm{H}$, Kahramanoglu O, Verit FF, Yucel O. What influences women's contraceptive choice? A crosssectional study from Turkey. Ginekol Pol. 2017;88:639-46.

3. Wallace HJ, McDonald S, Belton S, Miranda AI, da Costa E, da Conceicao Matos L, et al. What influences a woman's decision to access contraception in Timor-Leste? Perceptions from Timorese women and men. Cult Health Sex. 2018;6:1-16.

4. Minnis AM, Roberts ST, Agot K, Weinrib R, Ahmed $\mathrm{K}$, Manenzhe K, et al. Young Women's Ratings of Three Placebo Multipurpose Prevention Technologies for HIV and Pregnancy Prevention in a Randomized, Cross-Over Study in Kenya and South Africa. AIDS Behav. 2018.

5. Available at: https://advancefamilyplanning.org/sites/default/files/ resources/FP2020-Vision-Document\%20India.pdf. Accessed on 3 April 2018

6. Shoupe D. LARC methods: entering a new age of contraception and reproductive health. Contracept Reprod Med. 2016;1:4

7. Ihongbe TO, Masho SW. Changes in the use of longacting reversible contraceptive methods among U.S. nulliparous women: results from the 2006-2010, 2011-2013, and 2013-2015 National Survey of Family Growth. J Womens Health (Larchmt). 2018;27:245-52.

8. Stoddard A, McNicholas C, Peipert JF. Efficacy and safety of long-acting reversible contraception. Drugs. 2011;71:969-80.

9. Available at: https://www.k4health.org/sites/default/files/BMGF\% 20Fact\%20Sheet\%20June\%202012.pdf. Accessed on 8 April 2018.

10. Kant S, Archana S, Singh AK, Ahamed F, Haldar P. Acceptance rate, probability of follow-up, and expulsion of postpartum intrauterine contraceptive device offered at two primary health centres, North India. J Family Med Prim Care. 2016;5:770-6.

11. Jairaj S, Dayyala S. A Cross Sectional Study on Acceptability and Safety of IUCD among Postpartum Mothers at Tertiary Care Hospital, Telangana. J Clin Diagn Res. 2016;10:1-4.

12. Gupta G, Goyal R, Kadam VK, Sharma P. The Clinical Outcome of Post Placental Copper-T-380A Insertion with Long Placental Forceps (Kelly's Forceps) After Normal Vaginal Delivery and Cesarean Section. J Obstet Gynecol Ind. 2015;65:386-8.

13. Kumar S, Sethi R, Balasubramaniam S, Charurat E, Lalchandani K, Semba R, Sood B. Women's experience with postpartum intrauterine contraceptive device use in India. Reprod Health. 2014;11:32-7.

14. Singal S, Bharti R, Dewan R, Divya, Dabral A, Batra A, Sharma M, Mittal P. Clinical Outcome of Postplacental Copper T 380A Insertion in Women Delivering by Caesarean Section. J Clin Diagn Res. 2014;8:1-4.

15. Halder A, Sowmya MS, Gayen A, Bhattacharya P, Mukherjee S, Datta S. A Prospective Study to Evaluate Vaginal Insertion and Intra-Cesarean Insertion of Post-Partum Intrauterine Contraceptive Device. J Obstet Gynecol Ind. 2016;66:35-41.

16. Secura GM, Allsworth JE, Madden T, Mullersman JL, Peipert JF. The Contraceptive CHOICE Project: reducing barriers to long-acting reversible contraception. Am J Obstet Gynecol. 2010;203:1-7.

17. Cleland K, Peipert JF, Westhoff C, Spear S, Trussell J. Family planning as a cost-saving preventive health service. N Engl J Med. 2011;364:37.

Cite this article as: Pal M, Roy SK. An analysis on choices of contraception. Int J Reprod Contracept Obstet Gynecol 2018;7:2792-5. 